\title{
Response of carbon and water fluxes to dryness/wetness in China
}

\author{
Xiaohan Zhao ${ }^{1}$, Fangmin Zhang ${ }^{1, *}$, Rongmingzhu $\mathrm{Su}^{2}$, Cao $\mathrm{Gao}^{3}$, and Kaicheng Xing ${ }^{4}$ \\ ${ }^{1}$ Collaborative Innovation Center on Forecast and Evaluation of Meteorological Disasters/Jiangsu Key Laboratory of \\ Agricultural Meteorology, Nanjing University of Information Science \& Technology, Nanjing, China \\ ${ }^{2}$ Institute of Tibetan Plateau Research, Chinese Academy of Sciences, Beijing, China \\ ${ }^{3}$ Guodian Environmental Protection Research Institute, Nanjing, China \\ ${ }^{4}$ Hebei Climate Center, Shijiazhuang, China
}

\section{Article history:}

Received 5 January 2020

Revised 19 August 2020

Accepted 25 August 2020

Keywords:

Precipitation Evapotranspiration Index (SPEI), Gross primary productivity (GPP), Evapotranspiration (ET), Water use efficiency (WUE), Dry/wet anomaly

Citation:

Zhao, X., F. Zhang, R. Su, C. Gao, and K. Xing, 2021: Response of carbon and water fluxes to dryness/ wetness in China. Terr. Atmos. Ocean. Sci., 32, 53-67, doi: 10.3319/ TAO.2020.08.25.01

\begin{abstract}
Carbon-water cycle of terrestrial ecosystem is the important process of energy and mass exchanges, which is greatly influenced by changes of wet/dry conditions. Recently, China is experiencing frequent extreme weather events. Many concerns have been raised to explore how and to what extent dryness/wetness have influenced the carbon-water cycle in China on the regional scale. In this study, we examined the effects of changes of dryness/wetness on gross primary productivity (GPP), evapotranspiration (ET), and water use efficiency (WUE) in terrestrial ecosystems of China during 2001 - 2013 using standardized wet/dry anomaly index and Mann-Kendall method. Our analysis indicated that droughts hit extensively in 2001, 2006, 2009, and 2011, in contrast, extremely severe floods occurred in 2002, 2003, and 2010. Spatially, droughts increased obviously in south China but were alleviated in north China from 2001 to 2013. On average, GPP and WUE of China exhibited increasing trends but ET exhibited a decreasing trend. Severe dry/wet conditions (ISPEII > 1) decreased GPP, ET, and WUE. Furthermore, the effect of dry stress on GPP, ET, and WUE was much more serious than the effect of wet stress. It was implied that the trends of GPP, ET, and WUE would not change greatly on the long-term scale, but extreme dry/wet events would enhance their change amplitudes in future.
\end{abstract}

\section{INTRODUCTION}

The carbon and water cycle known as an important ecological coupling process is the basic biophysical process of surface energy exchange and material circulation ( $\mathrm{Yu}$ et al. 2004). Its imbalance would further exacerbate global climate change. For example, the increasing $\mathrm{CO}_{2}$ concentration in the atmosphere causes global warming, which would cause regional precipitation imbalances and enhance extreme weather events such as droughts and floods (Oliver 2005). Droughts and floods would cause soil moisture anomalies that affect the supply of water to plant roots, which in turn affects the carbon assimilation and evapotranspiration (Van der Molen et al. 2011).

There are several climate-based indicators to assess climate dryness and wetness (Asadi Zarch et al. 2015; Zhao et al. 2017; Zhang et al. 2019). They can be classified as two

\footnotetext{
* Corresponding author

E-mail:Fmin.zhang@nuist.edu.cn
}

types: one is using climate data and probabilistic calculation such as the Standardized Precipitation Index (SPI), the Standardized Precipitation Evapotranspiration Index (SPEI), and the other is based on water balance such as the Palmer Drought Severity Index (PDSI) and its variants. Under the background of global warming, SPEI not only needs less parameters and requires little computation, but it also takes into account temperature anomalies in drought on different time scales (Vicente-Serrano et al. 2012). Thus, SPEI and PDSI have been used widely to monitor dry and wet conditions in China (Zhao et al. 2017; Li et al. 2020).

In recent years, a series of studies have been carried out on the effects of droughts on the carbon and water cycle for both global and regional scales. For instance, the study of Ciais et al. (2005) showed that the decrease of summer precipitation and the extreme heat of 2003 in Europe caused a significant drop in gross primary productivity (GPP). Droughts of China resulted in the decline of net primary productivity (NPP) in the northwestern and eastern regions 
(Cheng et al. 2012; Zhao et al. 2014). Previous studies have shown that a much significant drier trend occurred in southwest and northeast of China during the last thirty years (Zou et al. 2010), whereas the frequency and intensity of floods in the southeast of China were on the rise (Liu and Xia 2016). The question is whether the effects of dryness and wetness on the carbon-water fluxes are the same in different regions of China?

This study aims to quantify dryness and wetness and evaluate the effects of dryness and wetness on the carbon and water flux of Chinese terrestrial ecosystem. We first analyzed the dryness and wetness characteristics of China, and then explored the responses of gross primary productivity (GPP), evapotranspiration (ET), and water use efficiency (WUE) to variations of dryness/wetness in China. This study will provide a better understanding of the feedback of extreme dry/wet events on the terrestrial ecosystem carbon and water cycle and provide a reference for the adaptation of ecosystem to extreme climate events.

\section{MATERIALS AND METHODOLOGY}

\subsection{Data Sources for Assessment of Dryness and Wetness}

We used three different datasets to distinguish dryness and wetness in China in this study.

Standardized Precipitation Evapotranspiration Index (SPEI) developed on the base of SPI by Vicente-Serrano et al. (2010), is widely used for drought monitoring on the background of global climate warming at present. The SPEI is characterized by multiple time-scales which can be chosen according to different research purposes (Zhao et al. 2017; Yao et al. 2018). In this study, the SPEI time series from 2000 to 2013 with a $0.5^{\circ}$ spatial resolution used to distinguish dry/wet condition of China is obtained from the Global SPEI database (http://spei.csic.es/database.html). The database is calculated based on monthly potential evapotranspiration (PET) in terms of the FAO Penman-Monteith method (Allen et al. 1994) using CRU TS3.2 monthly climate dataset from the Climatic Research Unit of the University of East Anglia (Harris et al. 2014). The detailed descriptions regarding the calculation of the SPEI database can be found in the study of Vicente-Serrano et al. (2010).

Self-calibrating Palmer Drought Severity Index (scPDSI) as a variant of the original PDSI was also developed based on soil water balance (Van der Schrier et al . 2013) but was designed more comparable for different climate regions relative to the original PDSI (Wells et al. 2004). On the other hand, scPDSI considers not only precipitation, temperature but also soil moisture compared with SPI and SPEI, so that it was also used widely for China drought studies in recent years (Wang et al. 2016b, 2017b). The scPDSI database similar as SPEI at the $0.5^{\circ}$ spatial resolution based on the FAO Penman-Monteith method using CRU TS3.2 monthly climate dataset from the Climatic Research Unit of the University of East Anglia was also chosen to distinguish dry/wet conditions of China (https://crudata.uea.ac.uk/cru/ data/drought/). The details for scPDSI calculation can be obtained in the study of Van der Schrier et al. (2013).

A comparison study revealed that SPEIs were suitable for monitoring short-term and long-term droughts while scPDSI for mid and long-term droughts in China (Zhao et al. 2017). Therefore, in this study, we only chose and compared the 3-month SPEI (Xu et al. 2015; Li et al. 2020) and scPDSI based on CRU climate datasets with China flood and drought disaster bulletin from Ministry of Water Resources (2014) to pick up the better indicator for dryness and wetness of China and further used the better one to describe and quantify the dry-wet distributions of China. The SPEI and scPDSI values and the corresponding dry/wet classifications are shown in Table 1. Since there are few vegetation in the bare lands of west China in Fig. 1, the region with bare lands was ignored to discuss in this study.

\subsection{GPP, ET, and WUE Data Sources}

The moderate resolution imaging spectroradiometer (MODIS) is an important satellite sensor of NASA Earth Observation System. Its ET and GPP products at $1 \mathrm{~km} \mathrm{spa-}$ tial resolution have been well validated and used widely across the world (Hu et al. 2015; Zeng et al. 2015). Lots of researches have used MODIS ET, GPP, and further calculated WUE by the ratio of GPP and ET in different regions of China (Mo et al. 2018; Tian and Zhang 2020). In this study, we used the MOD16A3 ET and MOD17A2 GPP from 2001 to 2013 (http://ntsg.umt.edu) and thereby calculated WUE in the corresponding period.

Another datasets of GPP, ET, and WUE from 2001 to 2013 with $1 \mathrm{~km}$ spatial resolution over China were obtained from Zhang et al. (2010, 2012, 2014). The GPP, ET, and WUE products were developed from a process-based daily BEPS model, and they had been also widely verified in China via comparing with flux data at different sites (Zhang et al. 2014; Liu et al. 2015).

Observational flux databases in 6 sites of mainland China compiled from AsiaFlux (http://www.asiaflux.net) were also used in this study, which can provide GPP and ET data for further MODIS and BEPS product validation and comparison. The vegetation types in 6 sites include needleleaf forest, broadleaved forest, mixed forest, grassland, and meadow. More details about the sites can be accessed from the Asiaflux website. The location of these sites is shown in Fig. 1.

\subsection{Assessment of Anomalies}

The standardized anomaly index (SAI) (Hamed and Rao 1998; Pei et al. 2013) is used to evaluate variable evolution: 
$\mathrm{Y}_{\mathrm{SAI}}(i)=[\mathrm{Y}(i)-\operatorname{Mean}(\mathrm{Y})] / \operatorname{Std}(\mathrm{Y})$

where $\mathrm{Y}(i)$ is the dependent variable in the $i$ year; Mean(Y) and $\operatorname{Std}(\mathrm{Y})$ are mean and standard deviation during the study period, $\mathrm{Y}_{\mathrm{SAI}}(i)$ is SAI for $\mathrm{Y}(i)$ in the $i$ year. The dependent variables $\mathrm{Y}$ in this study are SPEI, scPDSI, GPP, ET, and WUE. For instance, a series of SPEI values were input as the variable $\mathrm{Y}(i)$ and obtained $\mathrm{SPEI}_{\mathrm{SAI}}$, and SAIs of the other variables were calculated in the same way. The anomalies are classified into 5 categories: near normal $\left(\left|\mathrm{Y}_{\mathrm{SAI}}\right| \leq 0.5\right)$, slightly anomalous $\left(0.5<\left|\mathrm{Y}_{\mathrm{SAI}}\right| \leq 1\right)$, moderately anomalous $\left(1<\left|\mathrm{Y}_{\mathrm{SAI}}\right| \leq 1.5\right)$, severely anomalous $\left(1.5<\left|\mathrm{Y}_{\mathrm{SAI}}\right| \leq 2\right)$, and extremely anomalous $\left|\mathrm{Y}_{\mathrm{SAI}}\right|>2$.

\subsection{Mann-Kendall Test}

Mann-Kendall (MK) test is easy to calculate without particular distribution of samples and widely used for timing sequence analysis (Zhao and Running 2010). The test statistic $Z$ of variable statistic $S$ on time series $x$ :

$Z=\left\{\begin{array}{ccc}\frac{S-1}{\sqrt{\operatorname{Var}(S)}} & \text { if } & S>0 \\ 0 & \text { if } & S=0 \\ \frac{S+1}{\sqrt{\operatorname{Var}(S)}} & \text { if } & S<0\end{array}\right.$

where $\operatorname{Var}(S)$ is the variance of time series $x$. If $Z>0$, the time series $x$ exhibited an increasing trend; if $Z<0$, the time series $x$ exhibited a decreasing trend. The threshold values of $|Z|$ are $1.65,1.96$, and 2.57 at the significant level $p$ of $0.1,0.05,0.01$.

\section{RESULTS}

\subsection{GPP and ET Validation and Comparison}

Figure 2 presented the comparisons of observed annual GPP and ET against the corresponding GPP and ET values compiled from the BEPS model and the MODIS products. The GPP simulated by BEPS model explained $93 \%$ of the measured GPP $\left(\mathrm{R}^{2}=0.93, p<0.01\right)$, while the GPP from MODIS products explained $95 \%$ of the measured ET $\left(\mathrm{R}^{2}=0.95, p<0.01\right)$. Compared with the observed GPP, both of MODIS GPP and BEPS GPP can fit 1:1 line very well, and the relative errors were less than $11.26 \%$. As for ET, the BEPS model explained $70 \%$ of the measured ET $\left(\mathrm{R}^{2}=0.70, p<0.01\right)$, while the ET from MODIS products explained $77 \%$ of the measured ET $\left(\mathrm{R}^{2}=0.77, p<0.01\right)$. Compared with the observed ET, BEPS ET can fit 1:1 line well, but MODIS ET was overestimated at the high ET and underestimated at the low ET with the larger relative error of $15.18 \%$, despite that the relative error was still in the reasonable bounds. Spatially, GPP and ET from BEPS and
MODIS averaged during the period of 2001 - 2013 exhibited a similar distribution pattern; however, there were still some differences between the two products in some regions (Fig. A1). MODIS GPP and ET were larger than the corresponding BEPS GPP and ET product in the southeast region (relative bias of $10-30 \%$ ), and MODIS GPP was comparatively smaller in northeast region. The large relative biases between MODIS and BEPS products occurred in the Tibetan plateau and northwest bare region with low GPP and ET that was ignored in this study. Therefore, in order to reduce errors and make results more reasonable, we used the two-source GPP and ET ensembles from MODIS and BEPS to calculate WUE, and then the two-source-mean GPP, ET, and WUE were used to do further analysis.

\subsection{Variations of Dryness/Wetness in China}

According to SAI of the two drought indices used, both of SPEI and scPDSI had similar time trends (Figs. 3a and b). Both of the average annual SPEI and scPDSI were decreasing from 2002 to 2009 and then increasing, which showed China experienced wetting from the dry period after 2009. China was on average relatively dry in years of 2001, 2006, 2009 , and 2011 but was relatively wet in years of 2002, 2003, 2010, 2012, and 2013. The wetness in 2003 and 2010 and the dryness in 2001 and 2011 were the most serious ( $\left(\mathrm{SPEI}_{\mathrm{SAI}} \mathrm{I}>\right.$ 1) and widespread during the period of the study (Fig. 3e).

SPEI and scPDSI not only had obvious inter-annual variations, but also had significant spatial characteristics (Figs. A2 and A3). Generally, the spatial dry/wet changes based on SPEI were more consistent with actual dry/wet records from China flood and drought disaster bulletin of Ministry of Water Resources (2014). However, the dry/wet distribution based on scPDSI was shown much drier in China relative to the actual dry/wet records. For instance, 2010 was a typical wet year, SPEI can quickly capture dry/wet signals $\left(\left.\right|_{S P E I} I_{\mathrm{SAI}} \mid>1\right)$, but due to autoregressive characteristics, scPDSI was affected by the previous years (Guttman 1998), so it was still exhibiting drier in this wet year of 2010 (Figs. A2, A3, and A5). Therefore, we chose SPEI as the better indicator for dry and wet conditions of China to do further analysis in this study.

Spatially as shown in Fig. A2 based on SPEI, there were wide droughts in China especially in northern and middle regions in 2001 and 2006 but severe droughts widely distributed in south region in 2009 and 2011. For 2003, severe wetness occurred in the northwest and the middlenorth areas of southeast China, but droughts occurred in the southwest China. For 2005, the north central areas of China (e.g., middle of Inner Mongolia) also suffered heavy droughts. Several moderate droughts occurred in south China in 2007 but a normal condition followed in 2008. In 2010 and 2012, it was relatively wet in most region of China but drought patches scattered in southeast and southwest China. 
In general, the decreased SPEIs in some regions of southeast and east central China showed the drying trends with a 0.05 significance level (orange and red colors in Fig. 4a). In contrast, the increased SPEIs in regions of northeast of China showed the wetting trends with a significant increase $(p<0.05)$ (blue colors in Fig. 4a).

\subsection{Patterns of GPP, ET, and WUE and Responses to Dryness/Wetness}

The annual average GPP and ET were $718 \pm 51 \mathrm{gC} \mathrm{m}^{-2}$ $\mathrm{yr}^{-1}$, and $529 \pm 18 \mathrm{~mm} \mathrm{yr}^{-1}$, respectively. They were higher in the southeast China and smaller in the southwest China (Fig. A4). Temporally on the national scale, GPP showed a decreasing trend from 2002 to 2011 and then increased greatly with a rate of $30 \mathrm{gC} \mathrm{m}^{-2} \mathrm{yr}^{-1}$. The annual average GPP increased with a small rate of $2.3 \mathrm{gC} \mathrm{m}^{-2} \mathrm{yr}^{-1}$ during the 13 years due to significant decrease of GPP in 2001, 2010, $2011\left(\mathrm{GPP}_{\mathrm{SAI}}<-0.9\right)$ (Fig. 3e). As for ET, its change pattern was similar to GPP (Fig. 3d); however, it decreased slightly with a rate of $-0.3 \mathrm{~mm} \mathrm{yr}^{-1}$ during the study period due to the smaller increase after 2011 compared to GPP and significant decreases in 2001, 2006, 2009, and $2011\left(\mathrm{ET}_{\mathrm{SAI}}<-1.0\right)$.

The national annual average WUE was $0.07 \mathrm{gC} \mathrm{mm}^{-1}$.

Table 1. Dry/wet classification based on SPEI and scPDSI values (Alley 1984; Wang et al. 2018).

\begin{tabular}{cccccccc}
\hline Category & Severely dry & Moderately dry & Slightly dry & Normal & Slightly wet & Moderately wet & Severely wet \\
\hline dry/wet level & -3 & -2 & -1 & & 1 & 2 \\
SPEI value & $<-1.5$ & $-1.5 \sim-1.0$ & $-1.0 \sim-0.5$ & $-0.5 \sim 0.5$ & $0.5 \sim 1.0$ & $1.0 \sim 1.5$ & $>1.5$ \\
scPDSI value & $<-3.0$ & $-3.0 \sim-2.0$ & $-2.0 \sim-1.0$ & $-1.0 \sim 1.0$ & $1.0 \sim 2.0$ & $2.0 \sim 3.0$ & $>3.0$ \\
\hline
\end{tabular}

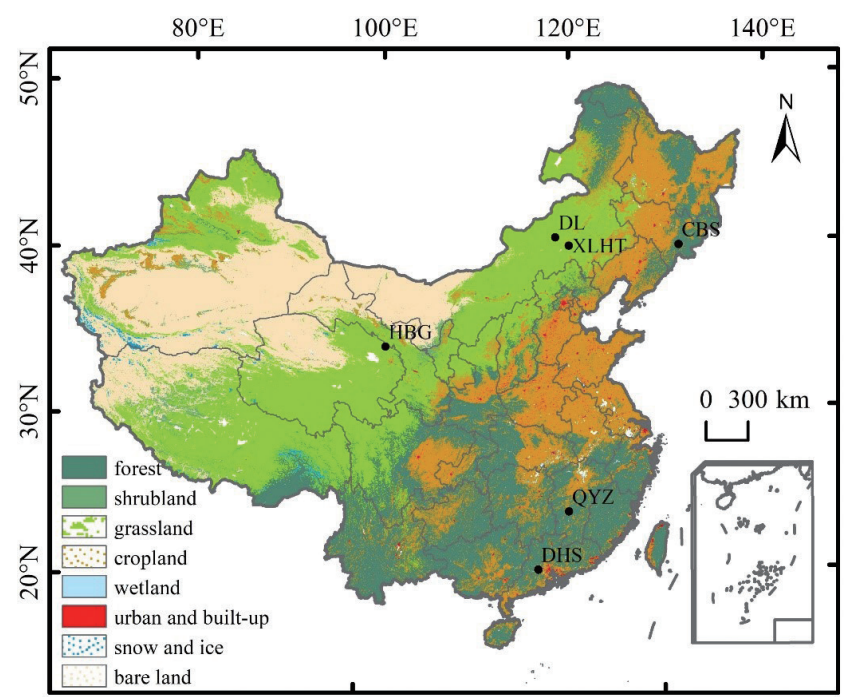

Fig. 1. The land cover map of China in 2013 from MODIS with 6 flux sites.
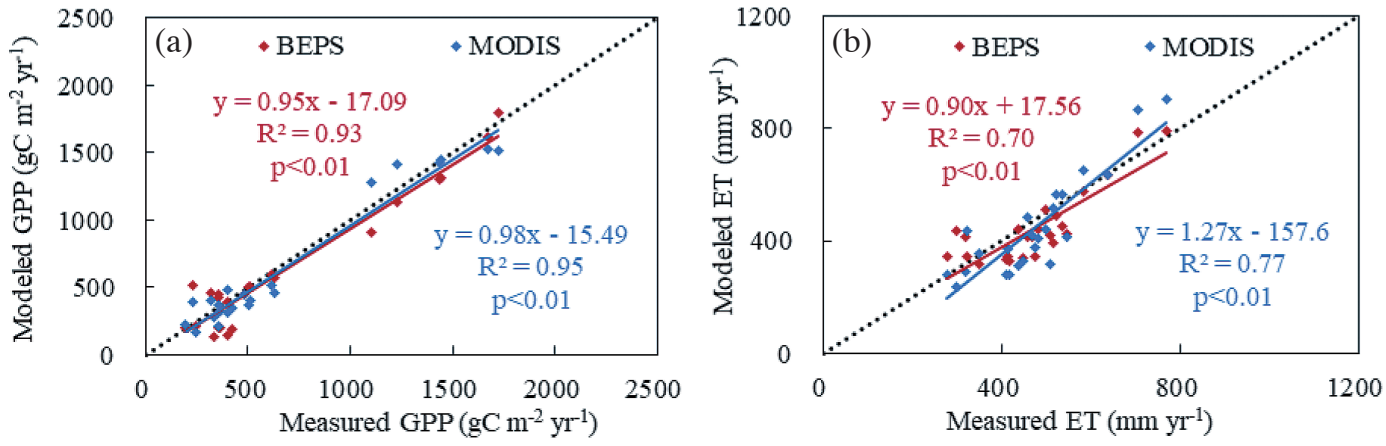

Fig. 2. Comparisons of measured annual GPP and ET with the corresponding GPP and ET compiled from MODIS and BEPS products. 


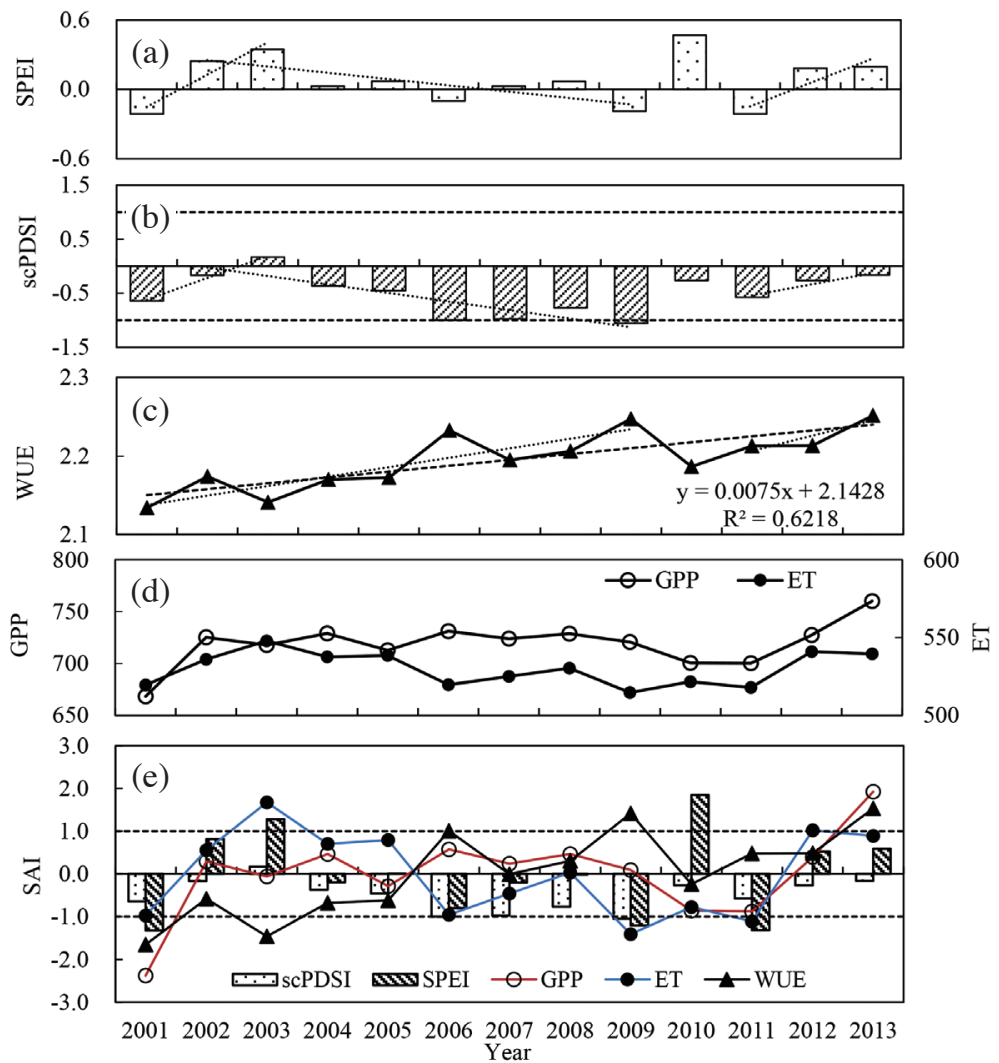

Fig. 3. Time trends and anomalies of annual mean SPEI, scPDSI, GPP $\left(\mathrm{gC} \mathrm{m}^{-2} \mathrm{yr}^{-1}\right)$, ET $\left(\mathrm{mm} \mathrm{yr}^{-1}\right)$, and WUE $\left(\mathrm{gC} \mathrm{mm}^{-1}\right)$ during $2001-2013$.
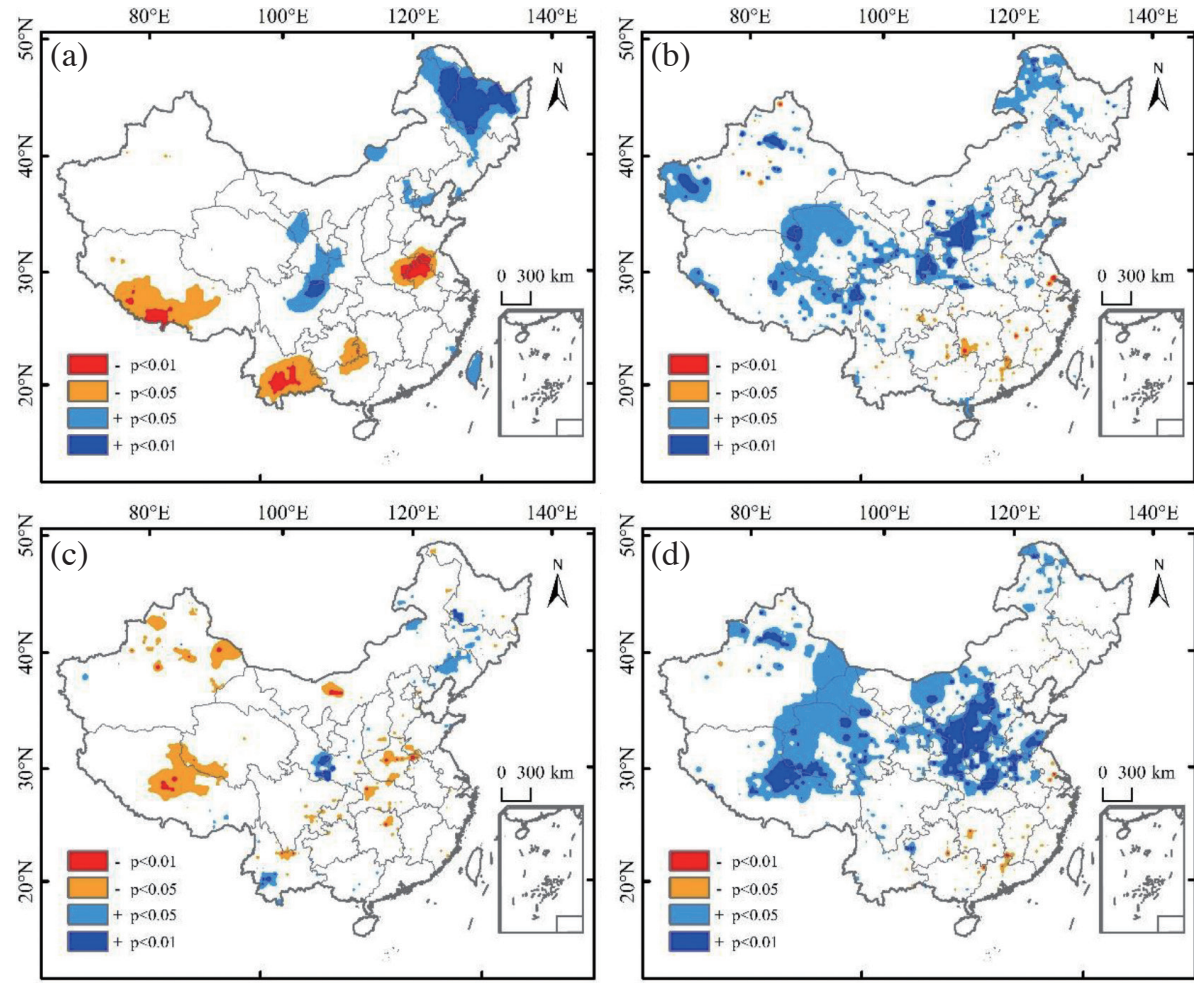

Fig. 4. Trends of SPEI (a), GPP (b), ET (c), and WUE (d) during 2001 - 2013 based on Mann-Kendall (MK) method (the colored areas passed the 0.05 significance level). 
Since ET decreased larger than GPP when SPEI decreased, but GPP increased larger than ET when SPEI increased during the study period, WUE exhibited a significantly increasing trend with the rate of $0.0075 \mathrm{gC} \mathrm{mm}^{-1} \mathrm{yr}^{-1}\left(\mathrm{R}^{2}=0.62, p\right.$ $<0.01)$ and $\mathrm{WUE}_{\mathrm{SAI}}$ was greater than 1.0 in 2006,2009 , and 2013 (Figs. 3c and e).

Comparison of GPP and ET with SPEI averaged on the national average scale (Fig. 3) showed that when SPEI was abnormal (i.e., under drought/wet conditions), both GPP and ET were relatively lower than average values. When $\left|\mathrm{SPEI}_{\mathrm{SAI}}\right|<1.5$, the averaged GPP and ET decreased with the decrease of SPEI, e.g., for the period of 2003 - 2009; or they increased with the increase of SPEI, e.g., for the period of $2001-2003$ and 2011 - 2013. At the same time, GPP was more sensitive than ET when SPEI increased (Fig. 3e).

Spatially, changes of GPP and WUE had the similar patterns (Figs. 4b and d). Areas with decreasing trends of GPP and WUE were distributed in the south China, and areas with increasing trends of GPP and WUE were distributed in the north China, especially in center-western China ( $p<$ 0.05) (blue colors in Figs. 4b and d). On the other hand, ET did not have a significant change in most of China, with only decreased in patchy areas of west and center-east China but increased in the patchy areas of center-south and northeast China with passing the 0.05 significant level (Fig. 4c). Basically, the change magnitude of ET was smaller than GPP. Compared with changes of SPEI on the long-term scale, changes of GPP and ET were positively related to changes of SPEI in most areas of China (Figs. 4a, b, and d); however, the relationship of GPP and SPEI was stronger than that of
ET and SPEI. Since WUE was directly determined by GPP and ET rather than SPEI, changes of WUE were not well correlated to changes of SPEI. The larger changes of GPP than ET made the spatial distribution of WUE trend more similar to GPP.

On the other hand, we found that relationships of GPP, ET, and WUE with SPEI differed at different SPEI ranges. Table 2 depicted the coefficients of GPP, ET, and WUE with SPEI based on SPEI values for the drought/wetness classification. They were negatively related to SPEI when SPEI was greater than 1.0 (i.e., under moderate and severe wet conditions), but positively related to SPEI when SPEI was less than 1.0. In other words, moderate and severe wet conditions can cause GPP $(p<0.05)$ and ET reduced, further on WUE $(p<0.05)$. In addition, moderate and severe dry condition can also reduce GPP, ET, and WUE greatly ( $p$ $<0.05)$. The influence of SPEI on GPP, ET, and WUE was not significant as a whole and did not pass the 0.05 significance level when ISPEIl $<1.0$. Generally, it suggests that the impact of moderate-above droughts was more severe than moderate-above wet condition to GPP and ET, but the moderate-above effects cannot be ignored.

\subsection{Comparisons of GPP and ET Changes in Two Extreme Years}

To further testify the influences of severe dry/wet condition on the spatial distribution of GPP and ET, we took the typical wet year of 2010 and the typical dry year of 2011 as examples (Figs. 5 and A5). According to anomalies

Table 2. Correlation coefficients of SPEI with GPP, ET, and WUE.

\begin{tabular}{ccccccc}
\hline SPEI & $\mathbf{< - 1 . 0}$ & $\mathbf{- 1 . 0} \sim \mathbf{- 0 . 5}$ & $\mathbf{- 0 . 5} \sim \mathbf{0}$ & $\mathbf{0} \sim \mathbf{0 . 5}$ & $\mathbf{0 . 5} \sim \mathbf{1 . 0}$ & $>\mathbf{1 . 0}$ \\
\hline GPP & $0.43^{* *}$ & 0.04 & -0.02 & 0.05 & 0.09 & $-0.14^{* *}$ \\
ET & $0.46^{* *}$ & 0.05 & 0.01 & 0.04 & 0.04 & -0.05 \\
WUE & $0.32^{* *}$ & 0.03 & 0.02 & 0.04 & $0.11^{* *}$ & $-0.14^{* *}$ \\
\hline \multicolumn{2}{r}{ Note: “*” represents significance at the 0.05 level, “**” represents significance at the 0.01 level. }
\end{tabular}
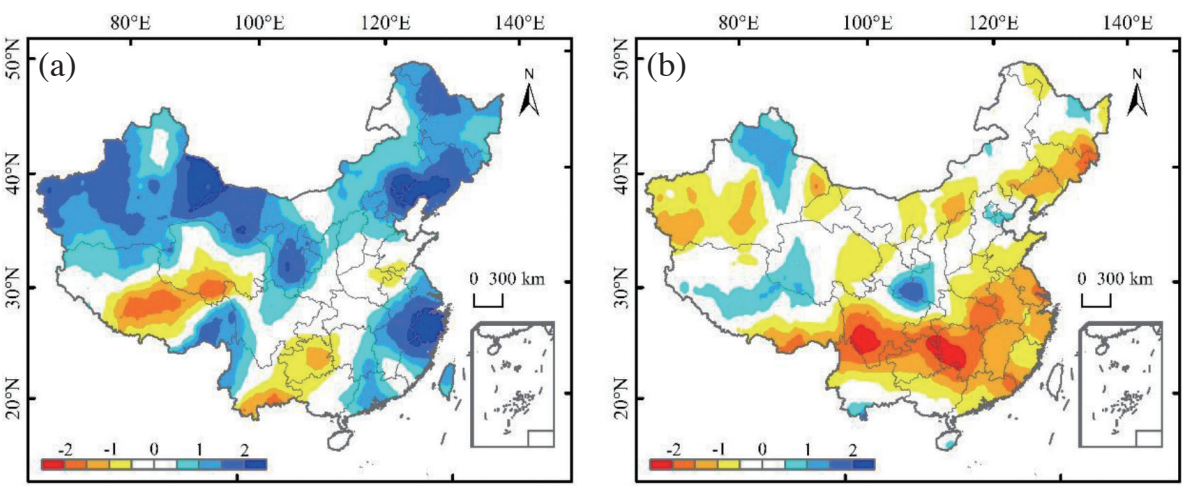

Fig. 5. Spatial distribution of SPEI $\mathrm{SAI}_{\mathrm{S}} 2010$ (a) and 2011 (b). 
of SPEI, GPP, ET, and WUE in 2010 and 2011 compared to the average of $2001-2013$, results shows that extreme drought/wetness with significant anomalies of SPEI (ISPEI) $>1,\left|\mathrm{SPEI}_{\mathrm{SAI}}\right|>1$ ) indeed trimmed GPP, ET, and WUE. However, the influence differed region by region.

As for the wet year of 2010, GPP decrease significantly $\left(\mathrm{GPP}_{\mathrm{SAI}}<-1\right)$ in most of the extreme wetting areas with significant anomalies of SPEI (SPEI $\left.\mathrm{SAI}_{\mathrm{I}}>1\right)$ such as northwest, northeast, and southeast China (Figs. 5a and 6a1). However, the decreased magnitude of $\mathrm{ET}\left(\mathrm{ET}_{\mathrm{SAI}}\right)$ in the northeast and northwest China was lower than in the southeast China (Fig. 6b1). Therefore, the decrease magnitude of (WUE $\left.\mathrm{WAI}_{\mathrm{SA}}\right)$ in the southeast China was not as noticeable as in the northeast and northwest China (Fig. 6c1). Meanwhile, the patchy severe droughts (SPEI $<-1$, SPEI SAI $_{2}<-1$ ) in southwest China also reduced GPP, ET, and WUE in 2010 (black box in
Figs. 6a1, b1, and c1).

As for the dry year of 2011, the novel droughts with significant anomalies centered in most of south China and scattered in areas of northeast China (Figs. 5 and A2). The effect of droughts caused GPP, ET, and WUE decrease significantly $(p<0.01)$ in south China. However, it caused GPP decrease smaller that ET (Figs. 6a and b), so that WUE did not decrease in all drought areas such as areas in black box of Fig. 6c2.

\section{DISCUSSION}

\subsection{Evaluation of Dryness/Wetness in China}

There are lots of factors influencing dry and wet patterns of a region over a period. In general, the most important factor is associate with precipitation from a climatic
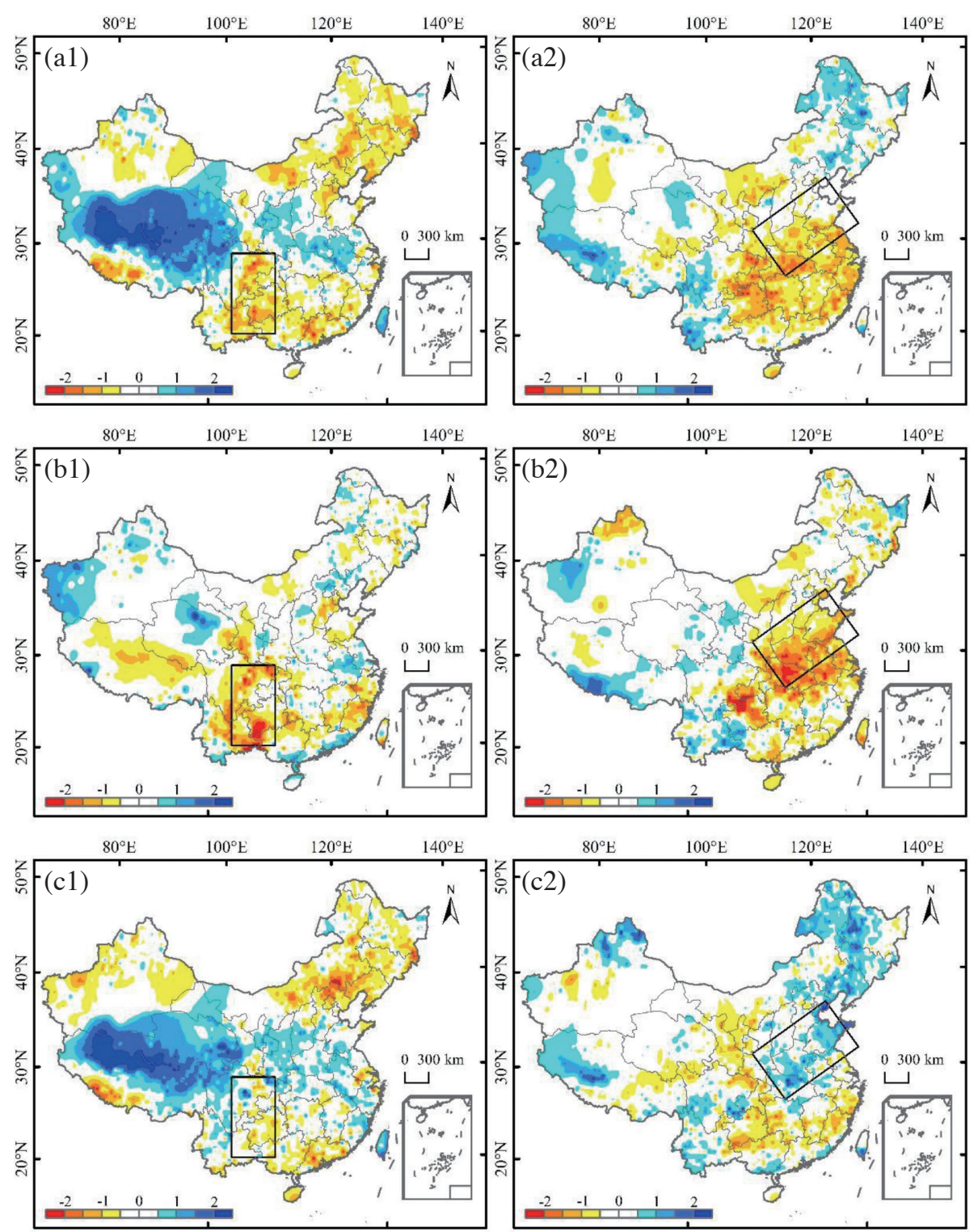

Fig. 6. Spatial distribution of $\mathrm{GPP}_{\mathrm{SAI}}$ (a), $\mathrm{ET}_{\mathrm{SAI}}(\mathrm{b})$, and $\mathrm{WUE}_{\mathrm{SAI}}$ (c) in 2010 (left panel) and 2011 (right panel). 
perspective. In order to quantify and monitor the dry/wet conditions, many indices have been developed (VicenteSerrano et al. 2010; Dai 2011; Zhuang et al. 2013; Wang et al. 2016a; Yang et al. 2017). In the context of climate change, some of indices have been used widely to study the spatial and temporal patterns of dryness/wetness over the world. However, most of research focused on patterns of droughts (Xu et al. 2015; Huang et al. 2018) but only several previous research studied the evolution of dryness and wetness. Based on 1-month SPEI, Lou et al. (2018) studied the temporal and spatial dryness and wetness patterns of Zhejiang Province over 1971 - 2015. Huang et al. (2017) and Wang et al. (2017a) investigated the variation of dryness and wetness in southeast costal region of China and Sichuan Province based on SPI, respectively. In this study, we used CRU 3-month SPEI and scPDSI datasets to investigate the temporal and spatial variations of dryness and wetness across China from 2001 to 2013. We found that CRU 3-month SPEI dataset was better to describe the dry and wet conditions of China. The finding was well consistent with the statistics in the bulletin of flood and drought disasters in China released by the Ministry of Water Resources (Ministry of Water Resources 2014).

\subsection{Effects of Dryness/Wetness on GPP, ET, and WUE}

A significant decreasing trend in GPP and ET with dryness/wetness was found, mostly at severe dryness/wetness conditions. The experiment on the rice by Liang et al. (2000) and on 6 maize types of Chen et al. (2005) showed WUE of crop increased under slight drought or water stress but significantly reduced under severe drought or water stress. Vicente-Serrano et al. (2013) found that plant biology change is sensitive to short-term drought in arid and humid areas, but sensitive to long drought in semi-arid and sub-humid areas (Vicente-Serrano et al. 2013). When drought happens, the top soil is dry and the deep soil is still humid. Hence, plants can absorb water from the soil and continue to assimilate carbon. Meanwhile, because of less of surface water, heterotrophic respiration is restricted. In this situation carbon assimilation will not be reduced but the reverse will occur. Chen et al. (2013) found SPEI and NPP were positively related in arid regions, but negatively in boreal regions. As the drought continued, the deep water gradually diminished and GPP, ET decreased significantly (Ju et al. 2006; Barr et al. 2009). Chen et al. (2013) indicated the influence of drought on NPP mostly occurred at areas with the most severe drought condition or after that, which is similar to our conclusion.

\subsection{Comparison of MODIS and BEPS Datasets in China}

GPP and ET from BEPS and MODIS showed the similar spatial distribution pattern, respectively; however, differences still existed in some regions (Fig. A1). MODIS GPP on the Tibetan plateau area was relatively smaller than BEPS GPP, but MODIS GPP was larger in the northwest China and southwest China. The large differences of ET occurred in the Tibetan plateau region, and MODIS ET was relatively larger. Comparatively speaking, MODIS ET was smaller than BEPS ET on grassland ecosystem with low vegetation coverage in the arid areas. On the whole, relative biases of annual ET and GPP from BEPS and MODIS mostly concentrated in $\pm 30 \%$ in the most regions of China except the bare lands and Tibetan plateau region in west China. In order to reduce the uncertainties arising from different models and driving forces, thus we used a multi-model ensemble GPP and ET products to do analysis in this study.

\subsection{Applicability of SPEI and ScPDSI in China}

Due to spatial comparability and rationality for monitoring dryness/wetness events, SPEI and scPDSI are the most widely used for the drought monitoring indices (Heim 2002; Zhuang et al. 2013). scPDSI is essentially based on a two-layer soil water balance model and is sensitive to soil moisture supply (Hao and Singh 2015). SPEI regarded as the combination of precipitation and PET can reflect climatic water balance (Hao and Singh 2015). It was shown that SPEI is better for humid region while PDSI and its variants for the arid and semiarid regions (Yang et al. 2017; Zhao et al. 2017). SPEI is also sensitive to the PET calculation schemes and the sensitivity differed with regions (Yang et al. 2017; Yao et al. 2018). For example, in the arid region such as Xinjiang, SPEI was mainly determined by PET (Yao et al. 2018) and a drier result was obtained using Thornthwaite method compared to the FAO PenmanMonteith method (Yang et al. 2017). Another study further revealed that it is more suitable to use scPDSI for long-term drought monitor due to the strong lagged autocorrelation (Zhao et al. 2017) since the calculation method of scPDSI considered the accumulated drought conditions in the previous months (Guttman 1998). scPDSI was suggested more comparable with 9-month to 19-month SPEI in China (Zhao et al. 2017). Our study used 3-month SPEI and scPDSI based on the FAO Penman-Monteith method in terms of CRU TS3.2 monthly climate datasets showed that the two indices had similar trends in the study period but fluctuations of SPEI were more pronounced and close to the actual wet/dry conditions in China (Figs. 3 and A2).

\subsection{Uncertainty and Limitations}

Due to the rapid economic growth and the launch of ecological conservation and restoration projects in China during the study period (Xiao 2014), urbanization and the establishment of ecological reserves may cause the change 
of GPP, ET, and WUE in regional and national terrestrial ecosystems (Shao et al. 2015), but these impacts were not included in this study. Over-wet phenomena would lead flooding and droughts might trigger other disasters such as plant diseases and insects. All of these indirect effects on GPP, ET, and WUE were also not to be considered. In addition, a study mentioned that the CRU dataset might overestimate the PET results compared with the China Meteorological Forcing Dataset (CMFD) and further can bring uncertainties to SPEI when using CRU dataset for SPEI ( $\mathrm{Li}$ et al. 2020). However, we only compared the comprehensive performances of 3-month SPEI and scPDSI in China based on the FAO Penman-Monteith method using CRU dataset in this study. Different input drivers also can introduce biases to SPEI or scPDSI and cause different conclusions for wet and dry analysis ( $\mathrm{Li}$ et al. 2020). Thus, more attention should be paid to not only the calculation methods but also the inputs when objective drought indices are chosen to use in the future.

\section{CONCLUSION}

We evaluated the dry/wet changes of China using SPEI and scPDSI based on the FAO Penman-Monteith method in terms of CRU TS3.2 monthly climate datasets, and further examined effects of dry/wet conditions on GPP, ET, and WUE in ecosystems of China during 2001 to 2013. In order to reduce the uncertainty caused by model assumptions and driving forces, we also used two-source GPP and ET from MODIS and BEPS for comparison.

In general, CRU SPEI can roughly delineate better than CRU scPDSI for dry/wet conditions in China compared with China flood and drought disaster bulletin from Ministry of Water Resources. CRU SPEI and CRU scPDSI had the similar trends but CRU SPEI tended to identify the frequent drought events and approach to the actual conditions while CRU scPDSI was likely overestimate drought events due to the strong lagged autocorrelation. Given the fact that the fluctuation of climate change becomes more frequent in the future, CRU SPEI may be more suitable widely used for the dry/wet monitoring in China. Based on CRU SPEI, severe droughts occurred in 2001, 2006, 2009, and 2011, in contrast, extremely severe wet events occurred in 2002, 2003, and 2010. Spatially, droughts were enhanced obviously in areas of the southwest China whereas they were alleviated in areas of the northeast China.

Changes of GPP and ET were positively related to changes of SPEI in most areas of China; however, the responses of GPP and ET to SPEI differed with SPEI magnitudes, resulting that changes of WUE were not well correlated to changes of SPEI. In summary, moderate and severe dry and wet conditions had an adverse effect on GPP, ET, and WUE, and the influence of drought stress was much more than water stress as a whole; however, the influence of water stress should not be ignored.

Acknowledgements This research was partially supported by the National Key R\&D Program of China (2018YFC1506606), and funded by the Provincial Youth Foundation of Jiangsu (BK20170102). We acknowledge anonymous reviewers for thoughtful comments and suggestions for improving the manuscript.

\section{REFERENCES}

Allen, R. G., M. Smith, A. Perrier, and L. S. Pereira, 1994: An update for the calculation of reference evapotranspiration. ICID Bull., 43, 35-92.

Alley, W. M., 1984: The Palmer Drought Severity Index: Limitations and Assumptions. $J$. Appl. Meteorol. Climatol., 23, 1100-1109, doi: 10.1175/1520-0450(1984)023<1100:TPDSIL>2.0. $\mathrm{CO} ; 2$. [Link]

Asadi Zarch, M. A., B. Sivakumar, and A. Sharma, 2015: Droughts in a warming climate: A global assessment of Standardized precipitation index (SPI) and Reconnaissance drought index (RDI). J. Hydrol., 526, 183-195, doi: 10.1016/j.jhydrol.2014.09.071. [Link]

Barr, A., T. A. Black, and H. McCaughey, 2009: Climatic and phenological controls of the carbon and energy balances of three contrasting boreal forest ecosystems in western Canada. In: Noormets, A. (Ed.), Phenology of Ecosystem Processes: Applications in Global Change Research, Springer, New York, 3-34, doi: 10.1007/978-1-4419-0026-5_1. [Link]

Chen, J., X. Ma, W. Yang, Z. Cui, and B. Ling, 2005: Effects of water stress on yield and water use efficiency of maize in heading stage. Crops, 2005, 20-23, doi: 10.3969/j.issn.1001-7283.2005.02.008. [Link]

Chen, T., G. R. van der Werf, R. A. M. de Jeu, G. Wang, and A. J. Dolman, 2013: A global analysis of the impact of drought on net primary productivity. Hydrol. Earth Syst. Sci., 17, 3885-3894, doi: 10.5194/hess-17-38852013. [Link]

Cheng, M., R. Wang, H. Xue, and Q. Li, 2012: Effects of drought on ecosystem net primary production in northwestern China. J. Arid Land Res. Environ., 26, 1-7, doi: 10.13448/j.cnki.jalre.2012.06.026. [Link]

Ciais, P., M. Reichstein, N. Viovy, A. Granier, J. Ogée, V. Allard, M. Aubinet, N. Buchmann, C. Bernhofer, A. Carrara, F. Chevallier, N. De Noblet, A. D. Friend, P. Friedlingstein, T. Grünwald, B. Heinesch, P. Keronen, A. Knohl, G. Krinner, D. Loustau, G. Manca, G. Matteucci, F. Miglietta, J. M. Ourcival, D. Papale, K. Pilegaard, S. Rambal, G. Seufert, J. F. Soussana, M. J. Sanz, E. D. Schulze, T. Vesala, and R. Valentini, 2005: Europe-wide reduction in primary productivity caused by the heat and drought in 2003. Nature, 437, 529-533, 
doi: 10.1038/nature03972. [Link]

Dai, A., 2011: Characteristics and trends in various forms of the Palmer Drought Severity Index during 1900-2008. J. Geophys. Res., 116, doi: 10.1029/2010jd015541. [Link]

Guttman, N. B., 1998: Comparing the Palmer Drought Index and the Standardized Precipitation Index. J. Am. Water Resour. Assoc., 34, 113-121, doi: 10.1111/ j.1752-1688.1998.tb05964.x. [Link]

Hamed, K. H. and A. R. Rao, 1998: A modified Mann-Kendall trend test for autocorrelated data. J. Hydrol., 204, 182-196, doi: 10.1016/S0022-1694(97)00125-X. [Link]

Hao, Z. and V.P. Singh, 2015: Drought characterization from a multivariate perspective: A review. J. Hydrol., 527, 668-678, doi: 10.1016/j.jhydrol.2015.05.031. [Link]

Harris, I., P. D. Jones, T. J. Osborn, and D. H. Lister, 2014: Updated high-resolution grids of monthly climatic observations - the CRU TS3.10 dataset. Int. J. Climatol., 34, 623-642, doi: 10.1002/joc.3711. [Link]

Heim, R. R., 2002: A review of twentieth-century Drought Indices used in the United States. Bull. Amer. Meteorol. Soc., 83, 1149-1166, doi: 10.1175/1520-047783.8.1149. [Link]

$\mathrm{Hu}, \mathrm{G} ., \mathrm{L}$. Jia, and M. Menenti, 2015: Comparison of MOD16 and LSA-SAF MSG evapotranspiration products over Europe for 2011. Remote Sens. Environ., 156, 510-526, doi: 10.1016/j.rse.2014.10.017. [Link]

Huang, C., Q. Zhang, V. P. Singh, X. Gu, and P. Shi, 2017: Spatio-temporal variation of dryness/wetness across the Pearl River basin, China, and relation to climate indices. Int. J. Climatol., 37, 318-332, doi: 10.1002/ joc.5005. [Link]

Huang, J., J. Zhai, T. Jiang, Y. Wang, X. Li, R. Wang, M. Xiong, B. Su, and T. Fischer, 2018: Analysis of future drought characteristics in China using the regional climate model CCLM. Clim. Dyn., 50, 507-525, doi: 10.1007/s00382-017-3623-z. [Link]

Ju, W., J. M. Chen, T. A. Black, A. G. Barr, J. Liu, and B. Chen, 2006: Modelling multi-year coupled carbon and water fluxes in a boreal aspen forest. $A g$ ric. For. Meteorol., 140, 136-151, doi: 10.1016/j. agrformet.2006.08.008. [Link]

Li, L., D. She, H. Zheng, P. Lin, and Z.-L. Yang, 2020: Elucidating diverse drought characteristics from two meteorological drought indices (SPI and SPEI) in China. J. Hydrometeorol., 21, 1513-1530, doi: 10.1175/jhmd-19-0290.1. [Link]

Liang, M., Z. Tan, L. Chen, G. Zhou, B. Lei, and Z. Jiang, 2000: Influence of drought stress on water use efficiency of paddy rice. Life Sci. Res., 4, 351-355, doi: 10.3969/j.issn.1007-7847.2000.04.012. [Link]

Liu, Y., J. Xiao, W. Ju, Y.Zhou, S. Wang, and X. Wu, 2015: Water use efficiency of china's terrestrial ecosystems and responses to drought. Sci. Rep., 5, doi: 10.1038/ srep13799. [Link]

Liu, Z. and J. Xia, 2016: Impact of climate change on flood disaster risk in China. Chin. J. Nat., 38, 182-188, doi: 10.3969/j.issn.0253-9608.2016.03.003. [Link]

Lou, W., L. Wu, Y. Mao, and K. Sun, 2018: Precipitation and temperature trends and dryness/wetness pattern during 1971-2015 in Zhejiang Province, southeastern China. Theor. Appl. Climatol., 133, 47-57, doi: 10.1007/s00704-017-2134-5. [Link]

Ministry of Water Resources, 2014: China Flood and Drought Disaster Bulletin (2013), China Water Resources and Hydropower Press, Ministry of water resources, P.R. China, 34-38.

Mo, X., S. Liu, X. Chen, and S. Hu, 2018: Variability, tendencies, and climate controls of terrestrial evapotranspiration and gross primary productivity in the recent decade over China. Ecohydrology, 11, e1951, doi: 10.1002/eco.1951. [Link]

Oliver, J. E., 2005: Intergovernmental Panel in Climate Change (IPCC). In: Oliver, J. E. (Ed.), Encyclopedia of World Climatology, Encyclopedia of Earth Sciences Series, Springer Netherlands, Dordrecht, 48-56, doi: 10.1007/1-4020-3266-8_109. [Link]

Pei, F., X. Li, X. Liu, and C. Lao, 2013: Assessing the impacts of droughts on net primary productivity in China. J. Environ. Manage., 114, 362-371, doi: 10.1016/j.jenvman.2012.10.031. [Link]

Shao, S., F. Li, and J. Zhang, 2015: Impact of nitrogen and phosphorus limitation on carbon cycle of forest ecosystem in the Greater Khingan Mountains. J. B. Normal Univ. (Nat. Sci.), 51, 306-312, doi: 10.16360/j. cnki.jbnuns.2015.03.015. [Link]

Tian, F. and Y. Zhang, 2020: Spatiotemporal patterns of evapotranspiration, gross primary productivity, and water use efficiency of cropland in agroecosystems and their relation to the water-saving project in the Shiyang River Basin of Northwestern China. Comput. Electron. Agric., 172, 105379, doi: 10.1016/j.compag.2020.105379. [Link]

Van der Molen, M. K., A. J. Dolman, P. Ciais, T. Eglin, N. Gobron, B. E. Law, P. Meir, W. Peters, O. L. Phillips, M. Reichstein, T. Chen, S. C. Dekker, M. Doubková, M. A. Friedl, M. Jung, B. J. J. M. van den Hurk, R. A. M. de Jeu, B. Kruijt, T. Ohta, K. T. Rebel, S. Plummer, S. I. Seneviratne, S. Sitch, A. J. Teuling, G. R. van der Werf, and G. Wang, 2011: Drought and ecosystem carbon cycling. Agric. For. Meteorol., 151, 765-773, doi: 10.1016/j.agrformet.2011.01.018. [Link]

Van der Schrier, G., J. Barichivich, K. R. Briffa, and P. D. Jones, 2013: A scPDSI-based global data set of dry and wet spells for 1901-2009. J. Geophys. Res., 118, 40254048, doi: 10.1002/jgrd.50355. [Link]

Vicente-Serrano, S. M., S. Beguería, and J. I. LópezMoreno, 2010: A multiscalar drought index sensitive 
to global warming: The standardized precipitation evapotranspiration index. J. Clim., 23, 1696-1718, doi: 10.1175/2009JCLI2909.1. [Link]

Vicente-Serrano, S. M., S. Beguería, J. Lorenzo-Lacruz, J. J. Camarero, J. I. López-Moreno, C. Azorin-Molina, J. Revuelto, E. Morán-Tejeda, and A. Sanchez-Lorenzo, 2012: Performance of drought indices for ecological, agricultural, and hydrological applications. Earth Interact., 16, 1-27, doi: 10.1175/2012EI000434.1. [Link]

Vicente-Serrano, S. M., C. Gouveia, J. J. Camarero, S. Beguería, R. Trigo, J. I. López-Moreno, C. AzorínMolina, E. Pasho, J. Lorenzo-Lacruz, J. Revuelto, E. Morán-Tejeda, and A. Sanchez-Lorenzo, 2013: Response of vegetation to drought time-scales across global land biomes. Proc. Natl. Acad. Sci., 110, 52-57, doi: 10.1073/pnas.1207068110. [Link]

Wang, F., Z. Wang, H. Yang, and Y. Zhao, 2018: Study of the temporal and spatial patterns of drought in the Yellow River basin based on SPEI. Sci. China Earth Sci., 61, 1098-1111, doi: 10.1007/s11430-017-9198-2. [Link]

Wang, H., S. M. Vicente-Serrano, F. Tao, X. Zhang, P. Wang, C. Zhang, Y. Chen, D. Zhu, and A. E. Kenawy, 2016b: Monitoring winter wheat drought threat in Northern China using multiple climate-based drought indices and soil moisture during 2000-2013. Agric. For. Meteorol., 228-229, 1-12, doi: 10.1016/j. agrformet.2016.06.004. [Link]

Wang, R., J. Chen, X. Chen, and Y. Wang, 2017a: Variability of precipitation extremes and dryness/wetness over the southeast coastal region of China, 1960-2014. Int. J. Climatol., 37, 4656-4669, doi: 10.1002/joc.5113. [Link]

Wang, Z., Z. Huang, J. Li, and R. Zhong, 2016a: Assessing impacts of meteorological drought on vegetation at catchment scale in China based on SPEI and NDVI. Trans. Chin. Soc. Agric. Eng., 32, 177-186, doi: 10.11975/j.issn.1002-6819.2016.14.024. [Link]

Wang, Z., J. Li, C. Lai, Z. Zeng, R. Zhong, X. Chen, X. Zhou, and M. Wang, 2017b: Does drought in China show a significant decreasing trend from 1961 to 2009? Sci. Total Environ., 579, 314-324, doi: 10.1016/j.scitotenv .2016.11.098. [Link]

Wells, N., S. Goddard, and M. J. Hayes, 2004: A Self-Calibrating Palmer Drought Severity Index. J. Climate, 17, 2335-2351, doi: 10.1175/1520-0442(2004)017<2335: ASPDSI $>2.0 . \mathrm{CO} ; 2$. [Link]

Xiao, J., 2014: Satellite evidence for significant biophysical consequences of the "Grain for Green" Program on the Loess Plateau in China. J. Geophys. Res., 119, 22612275, doi: 10.1002/2014JG002820. [Link]

Xu, K., D. Yang, H. Yang, Z. Li, Y. Qin, and Y. Shen, 2015: Spatio-temporal variation of drought in China during 1961-2012: A climatic perspective. J. Hydrol., 526, 253-264, doi: 10.1016/j.jhydrol.2014.09.047. [Link]

Yang, Q., M. Li, Z. Zheng, and Z. Ma, 2017: Regional applicability of seven meteorological drought indices in China. Sci. China Earth Sci., 60, 745-760, doi: 10.1007/s1 1430-016-5133-5. [Link]

Yao, J., Y. Zhao, Y. Chen, X. Yu, and R. Zhang, 2018: Multi-scale assessments of droughts: A case study in Xinjiang, China. Sci. Total Environ., 630, 444-452, doi: 10.1016/j.scitotenv.2018.02.200. [Link]

Yu, G., Q. Wang, and Z. Yu, 2004: Study on the coupling cycle of water-carbon and process management in terrestrial ecosystem. Adv. Earth Sci., 19, 831-839, doi: 10.3321/j.issn:1001-8166.2004.05.022. [Link]

Zeng, T., Z. Zhang, X. Zhao, X. Wang, and L. Zuo, 2015: Evaluation of the 2010 MODIS Collection 5.1 Land Cover Type Product over China. Remote Sens., 7, 1981-2006, doi: 10.3390/rs70201981. [Link]

Zhang, F., W. Ju, J. Chen, S. Wang, G. Yu, Y. Li, S. Han, and J. Asanuma, 2010: Study on Evapotranspiration in East Asia using the BEPS Ecological Model. J. Nat. Resour., 25, 1596-1606, doi: 10.11849/ zrzyxb.2010.09.019. [Link]

Zhang, F., W. Ju, S. Shen, S. Wang, G. Yu, and S. Han, 2012: Variations of terrestrial net primary productivity in East Asia. Terr. Atmos. Ocean. Sci., 23, 425-437, doi: 10.3319/TAO.2012.03.28.01(A). [Link]

Zhang, F., W. Ju, S. Shen, S. Wang, G. Yu, and S. Han, 2014: How recent climate change influences water use efficiency in East Asia. Theor. Appl. Climatol., 116, 359-370, doi: 10.1007/s00704-013-0949-2. [Link]

Zhang, J., F. Sun, W. Lai, W. H. Lim, W. Liu, T. Wang, and P. Wang, 2019: Attributing changes in future extreme droughts based on PDSI in China. J. Hydrol., 573, 607 615, doi: 10.1016/j.jhydrol.2019.03.060. [Link]

Zhao, H., G. Gao, W. An, X. Zou, H. Li, and M. Hou, 2017: Timescale differences between SC-PDSI and SPEI for drought monitoring in China. Phys. Chem. Earth, 102, 48-58, doi: 10.1016/j.pce.2015.10.022. [Link]

Zhao, L., C. Xu, X. Liu, H. Li, H. Jiang, and A. Lin, 2014: Impacts of Meteorological Drought on Net Primary Productivity of Forest in HuBei Province. Resources and Environment in the Yangtze Basin, 23, 1595-1602, doi: 10.11870/cjlyzyyhj201411016. [Link]

Zhao, M. and S. W. Running, 2010: Drought-induced reduction in global terrestrial net primary production from 2000 through 2009. Science, 329, 940-943, doi: 10.1126/science.1192666. [Link]

Zhuang, S., H. Zuo, P. Ren, G. Xiong, B. Li, W. Dong, and L. Wang, 2013: Application of standardized precipitation evapotranspiration index in China. Clim. Environ. Res., 18, 617-625, doi: 10.3878/j.issn.10069585.2012.12007. [Link]

Zou, X., G. Ren, and Q. Zhang, 2010: Droughts variations in China based on a compound index of meteorological drought. Clim. Environ. Res., 15, 371-378, doi: 10.3878/j.issn.1006-9585.2010.04.04. [Link] 


\section{APPENDIX}
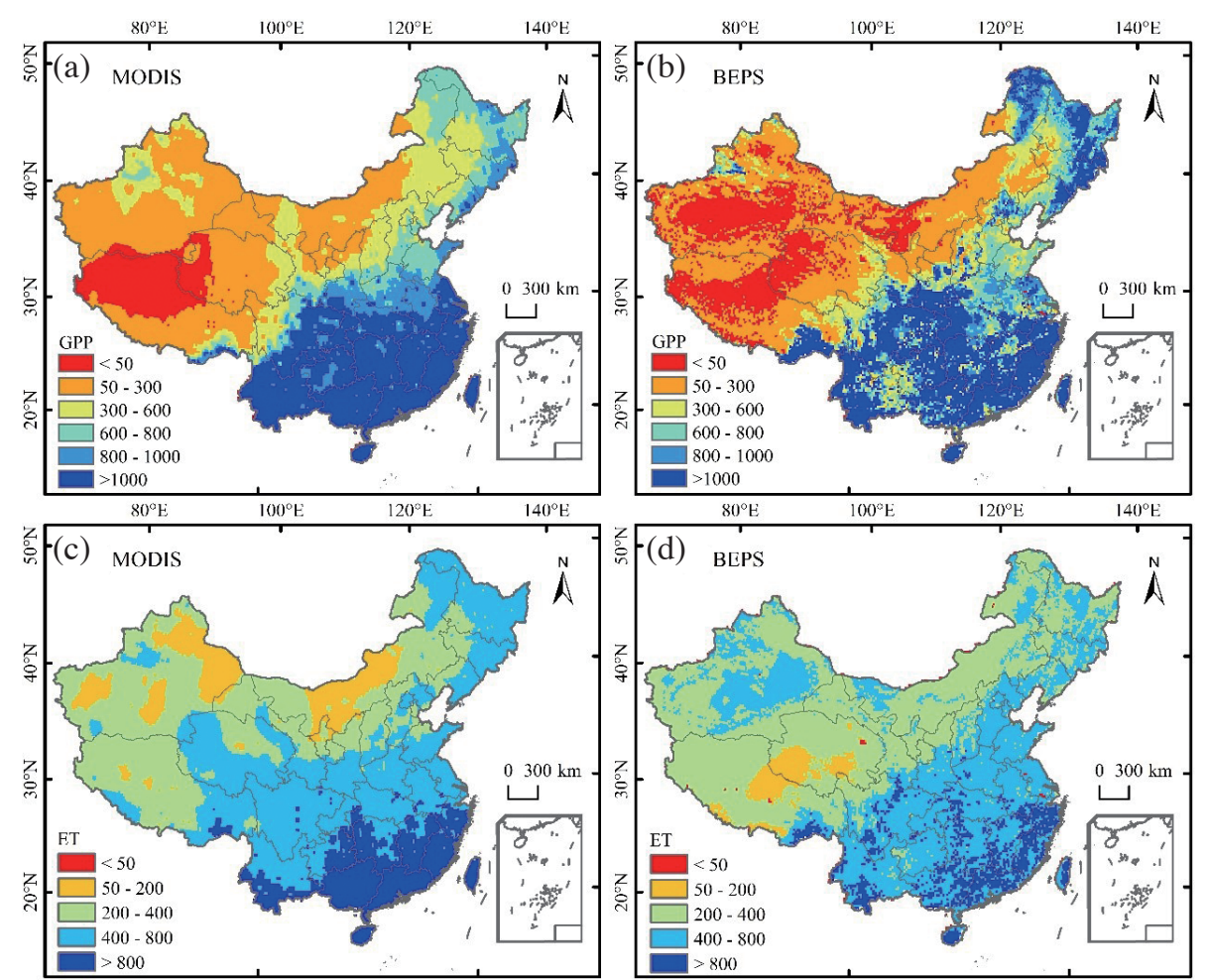

Fig. A1. Comparison of spatial patterns of 13-year-mean annual GPP $\left(\mathrm{gC} \mathrm{m}^{-2} \mathrm{yr}^{-1}\right)$ and ET $\left(\mathrm{mm} \mathrm{yr}^{-1}\right)$ of MODIS and BEPS. 

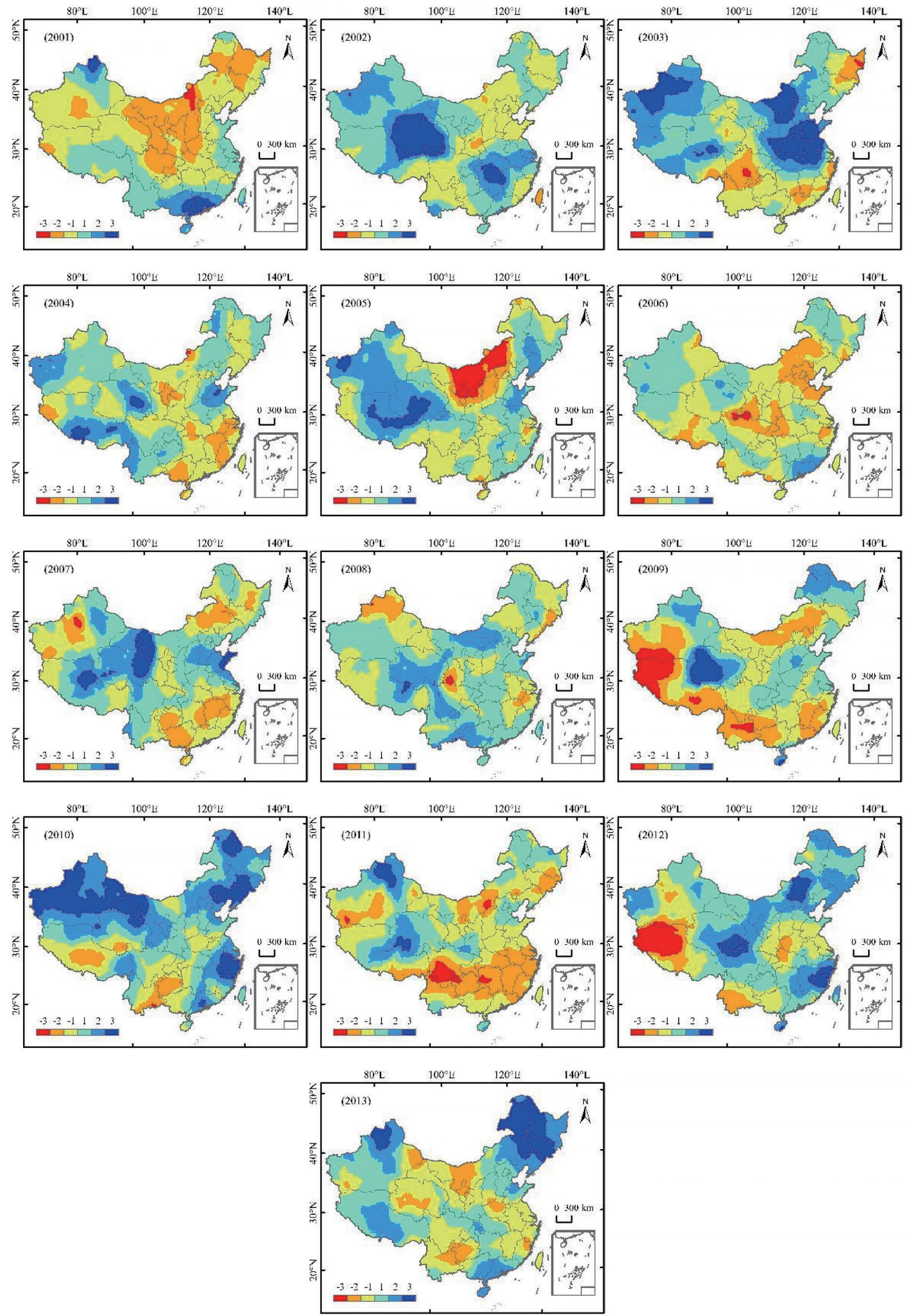

Fig. A2. Spatial patterns of SPEI during 2001 - 2013. The scalar value represents 6 dry/wet level classifications from severe dry to severe wet in Table 1. 

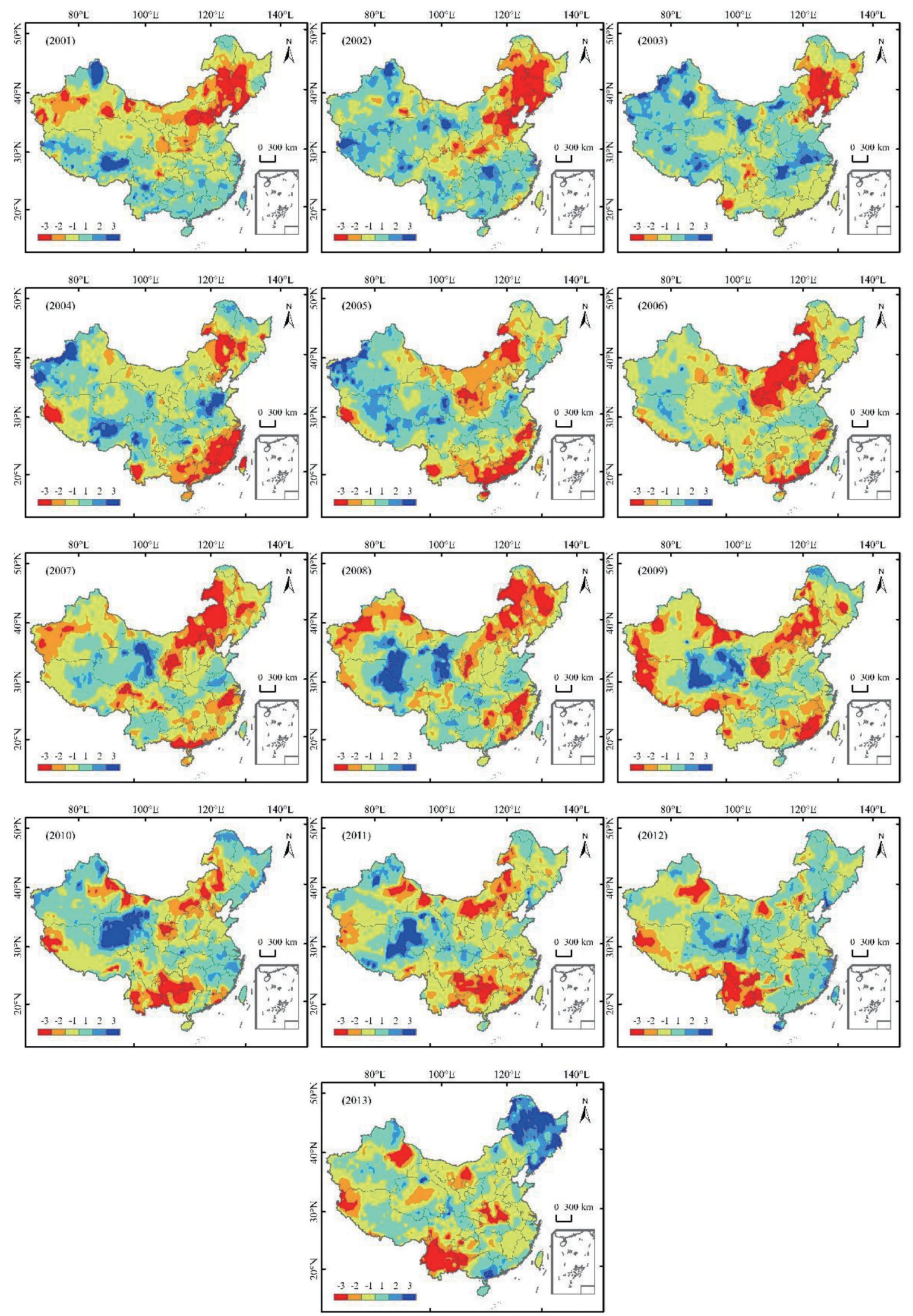

Fig. A3. Spatial patterns of scPDSI during 2001 - 2013. The scalar value represents 6 dry/wet level classifications from severe dry to severe wet in Table 1. 

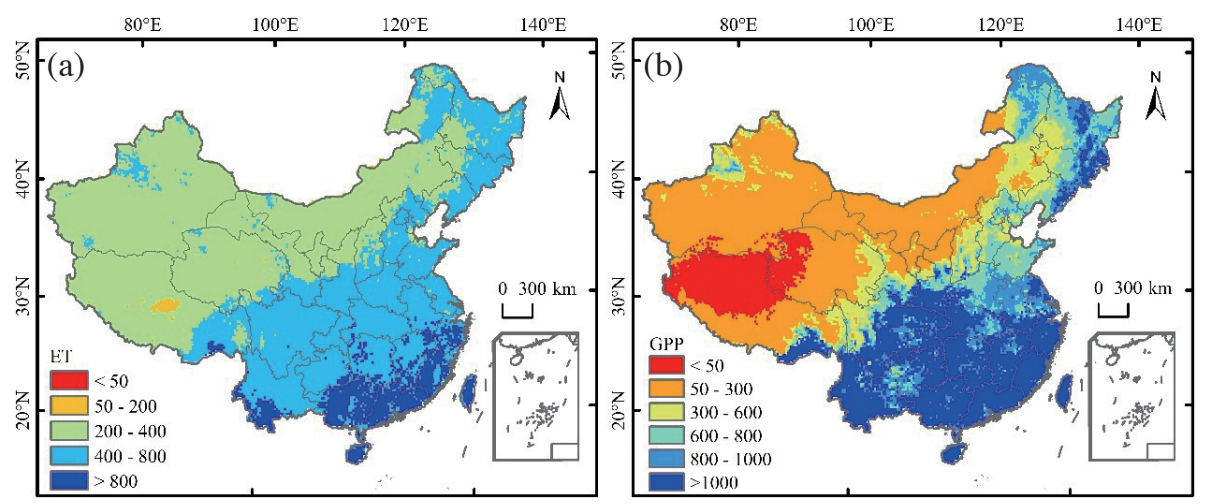

Fig. A4. Spatial patterns of two-source GPP $\left(\mathrm{gC} \mathrm{m}^{-2} \mathrm{yr}^{-1}\right)$ and ET $\left(\mathrm{mm} \mathrm{yr}^{-1}\right)$ averaged from MODIS and BEPS.
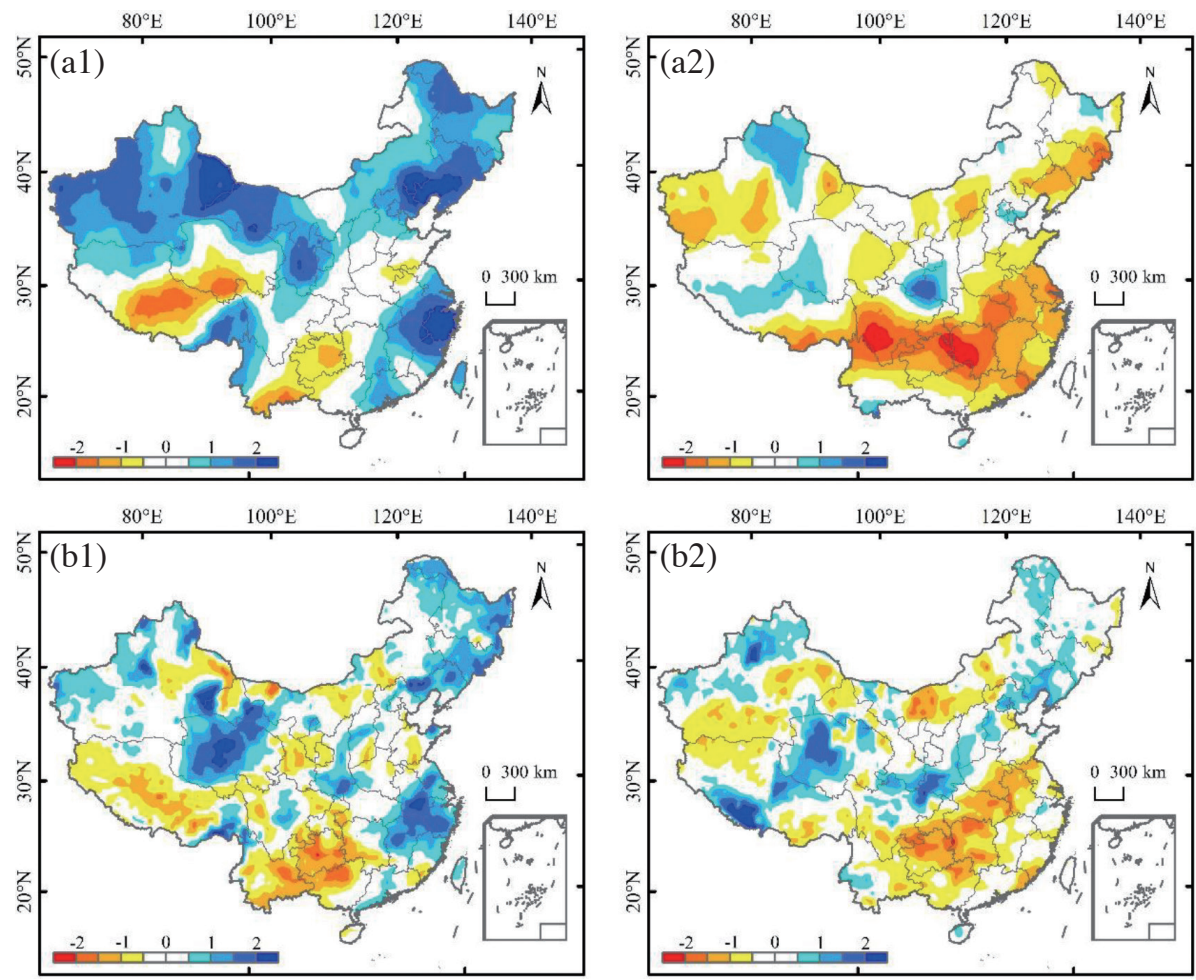

Fig. A5. Comparison of spatial distributions of SPEI $_{\mathrm{SAI}}$ in 2010 (a1) and 2011 (a2) and Spatial distributions of scPDSI SAI 2010 (b1) and 2011 (b2). 